\title{
ASSOCIATION OF ALLELES WITH CHROMOSOMAL COMPLEXES IN THE PERMANENT TRANSLOCATION HETEROZYGOTE, OENOTHERA LACINIATA
}

\author{
NORMAN C. ELLSTRAND* and DONALD A. LEVIN $\uparrow$ \\ * Department of Botany, Duke University, Durham NC 27706, U.S.A.; and \\ $\uparrow$ Department of Botany, University of Texas, Austin TX 787/2, U.S.A.
}

Received 7.viii.79

\section{Summary}

\begin{abstract}
Alleles are expected to be non-randomly distributed among rearranged chromosomal segments sheltered from recombination. Linkage analysis was carried out on 57 genomes representing 20 populations of the permanent translocation heterozygote, Oenothera laciniata, to determine the distribution of alleles among chromosomal complexes. For any given Pgi-1 heterozygote analysed, allelic inheritance was uniform and specific to each complex both among sibs and over the genomes tested. Certain developmental characters, manifested in hybrids with the related $O$. grandis, were also strongly associated with certain complexes; however, no other morphological characters, vegetative or floral, were found to be associated with either complex.
\end{abstract}

\section{INTRODUCTION}

Loci in chromosomally heterozygous regions of the genome are sheltered for recombination through the suppression of crossing-over (Grant, 1956). Certain alleles can become associated with such rearranged chromosomal segments (Hedrick et al., 1978). The association may be purely historical; alleles initially present on the rearranged segments or those arising from mutation may remain "locked" in their original position in the absence of crossing-over (Muller, 1964; Nei, 1970; Lokki, 1976; Charlesworth, 1978). Alternatively, blocks of linked genes may result from selection for " complexes of linked genes that are favourable in some particular combinations but not in others" (Dobzhansky, 1970). Finally, a neutral allele at one locus may " hitch-hike" when tightly linked to a favoured allele at a second locus (Kojima and Schaffer, 1967). Thus, the non-random association of alleles to rearranged chromosomal segments is expected to be common (Hedrick et al., 1978).

Most studies on the association of alleles among rearranged chromosomes has focused on electrophoretic alleles to inversion types in Drosophila. These studies have demonstrated that such associations frequently occur (reviewed in Ishii and Charlesworth, 1977; Hedrick et al., 1978).

Permanent translocation heterozygotes, those organisms that sexually breed true for a genome fully heterozygous for whole arm translocations, provide the greatest opportunity for allele-arrangement associations. The

* Present address: Dept. of Botany and Plant Sciences, University of California, Riverside, CA 92521. 
two haploid sets of chromosomes designated " complexes ", always segregate in these organisms. The two complexes are thus transmitted as "supergenes" (Carson, 1967). Permanent translocation heterozygosity occurs in a variety of plant species (Grant, 1975), but is especially prevalent and wellstudied in the genus Oenothera (Cleland, 1972).

The chromosomal complexes of the permanent translocation heterozygote, Oenothera biennis, and its allies have distinctive morphological syndromes; alleles determining these traits (leaf shape and texture, pubescence, etc.) are complex-specific (Cleland, 1972). Levy and Winternheimer (1977) found, for 51 races of $O$. biennis, " that groups of $\alpha$ (egg) and $\beta$ (sperm) complexes differ significantly in allelic frequencies at four of the six polymorphic loci (and all six when minority alleles are pooled). Allelic frequency differences are highly correlated with the alternate morphological syndromes . . . of the quasi-independent haploid genomes".

Do allele-arrangement relationships hold for other permanent translocation heterozygotes? Do they hold within and among natural populations? Answers were sought in populations of Oenothera laciniata Hill in Texas.

\section{Materials and Methods}

Oenothera laciniata is a permanent translocation heterozygote. All 14 chromosomes align themselves in a ring at meiotic metaphase I. Alternate disjunction then occurs, and crossing-over is restricted to the very tips of the chromosomes. Upon selfing, the complexes are reunited with balanced

TABLE 1

\begin{tabular}{ll}
\multicolumn{2}{c}{ Pgi-1 genotype frequencies* } \\
$b / d$ & $0 \cdot 32$ \\
$b / f$ & $0 \cdot 23$ \\
$d / d$ & $0 \cdot 23$ \\
$d / f$ & $0 \cdot 12$ \\
$b / b$ & $0 \cdot 04$ \\
$b / g$ & $0 \cdot 02$ \\
$d / g$ & $0 \cdot 02$ \\
$f / f$ & $0 \cdot 01$
\end{tabular}

* Based on 1040 individuals collected from 26 populations in Texas (Ellstrand, 1978).

lethals preventing the formation of chromosomally homozygous offspring (Hecht, 1950; Cleland, 1968; Ellstrand, 1978).

Reciprocal crosses between $O$. laciniata and its probable progenitor, the chromosomal homozygote, O. grandis Smyth (Ellstrand, 1978), were made to identify the location of alleles on the chromosomal complexes following the methods of Levy et al. (1975). When the ring-former is the egg parent, the alpha complex is transmitted; when it is the pollen parent, the beta complex is transmitted. Thus, by analysing progeny from reciprocal crosses of parents with known allozyme phenotype, it is possible to unambiguously assign an allele to a specific complex. 
TABLE 2

Location of Pgi 1 alleles and traits controlling floral development among races of $\mathrm{O}$. laciniata in $T_{\text {exas }}$

Population:

$\begin{array}{cc} & \text { Individual } \\ \text { L1 } & 1 \\ & 3 \\ & 8 \\ \text { L3 } & 8 \\ & 9 \\ \text { L4 } & 2 \\ & 11 \\ & 19 \\ & 23 \\ \text { L5 } & 7 \\ & 10 \\ \text { L6 } & 2 \\ & 4 \\ & 6 \\ & 7 \\ & 9 \\ \text { L7 } & 2 \\ & 8 \\ & 10 \\ \text { L8 } & 82 \\ & 84 \\ \text { L9 } & 83 \\ & 85 \\ & 86 \\ & 87 \\ \text { L10 } & 2\end{array}$

L10 2

L12 $\quad 17$

18

L14 $\quad 6$

L15 3

5
7
8

L16 3

L17 1

2
4
7

L19 6

L20 1

L22 63

98

L23

L24

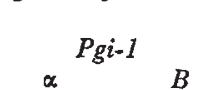

$a$
$d$
$d$
$d$
$g$
$g$
$d$
$d$
$d$
$d$
$f$
$f$
$f$
$f$
$f$
$f$
$f$
$f$
$f$
$f$
$d$
$d$
$d$
$d$
$d$
$d$$$
d
$$

$B$

$b$

$b$

Floral development
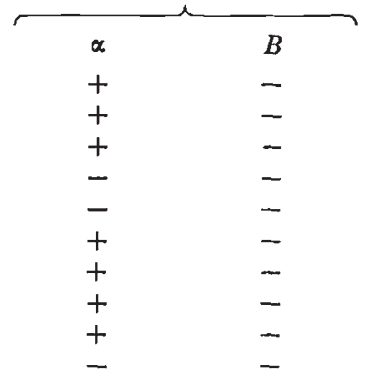
Seeds from five individuals of $O$. laciniata were collected in each of 20 Texas populations and were grown to maturity under greenhouse conditions. Immature buds were electrophoretically analysed to determine the allozyme phenotype of each plant. These plants were reciprocally crossed with $O$. grandis plants of known genotype. Pollen was obtained from a closed bud in which the anthers had dehisced. The pollen was transferred to the stigma of closed buds in which the anthers had not yet dehisced. The perianth and anthers of the egg parent were removed to avoid contamination by vagrant insects. Four progeny from each successful cross were analysed electrophoretically as seedlings. A fifth sib was grown to maturity; the length of the petals, corolla tube, anthers, filaments, and free tips of the sepals were recorded to determine whether any diagnostic characters were associated with either complex of $O$. laciniata.

The Pgi-1 locus was the subject of linkage analysis. Oenothera laciniata in Texas has four Pgi-1 alleles; the locus displays a heterozygote excess relative to Hardy-Weinberg expectations with 72 per cent heterozygosity (table 1; see Ellstrand, 1978). In a related chromosomal homozygote, $O$. grandis, alleles of the same electrophoretic mobility are inherited in a Mendelian fashion (see Ellstrand, 1978 for details of procedures and electromorphic mobilities).

\section{RESUlts}

Fifty-seven of the 100 pairs of reciprocal crosses yielded germinable seed. The allele-complex relationships determined from these progeny demonstrated that the inheritance of Pgi-1 alleles in 0 . laciniata is non-Mendelian. Allelic inheritance at this locus is uniform and specific to the direction of the cross.

Correlations of alleles to complexes are very strong. Individuals with the same heterozygous genotype have the same association of alleles to complexes both within and between populations (tables $2 \& 3$ ). The $d$ allele was found on the alpha complex for $b / d$ heterozygotes, but on the beta for $d / f$ and $d / g$ heterozygotes. The $f$ allele was found on the alpha complex for both $b / f$ and $d / f$ heterozygotes. The $g$ allele was associated with the alpha complex in $d / g$ individuals. And the $b$ allele was associated with the beta complex in both $b / d$ and $b / f$ heterozygotes. The $b / d, b / f$, and $d / f$ genotypes show significant linkage relationships $(\mathrm{P}<0.01,0.01$, and 0.05 ,

TABle 3

Summary of Pgi-1 allele locations in heterozygotes

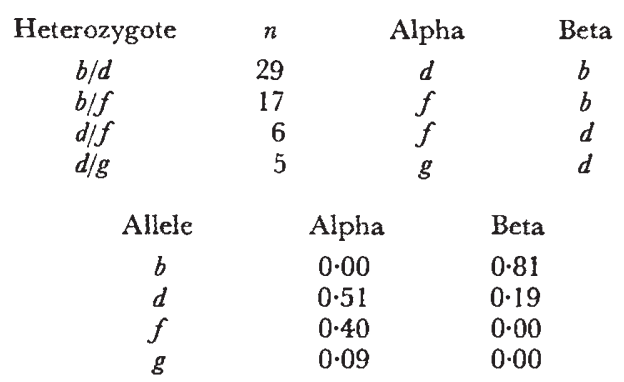


respectively) as determined by the two-tailed sign test (Hays and Winkler, 1971). Due to small sample size $(n=5)$, a significant linkage relationship cannot be shown for the $d / g$ heterozygotes although uniform linkage is apparent for these as well.

Developmental anomalies were correlated with the chromosomal complexes, too. Fl's included plants with aborted buds or no anthers, or anthers opening late (protogyny) (table 3). None of these conditions were observed in adults of either species. Four of the five cases of bud abortion occurred in plants receiving the alpha complex from $O$. laciniata, while all three plants without anthers received the beta complex. Protogyny was the most widespread developmental anomaly and is strongly associated with the beta complex, but not exclusively so (36 of 47 cases; $\mathrm{P}<0.001$; sign test). When associated with the alpha complex, this trait appeared, with one exception, in individuals with a $b / d P g i-1$ genotype. In ten cases, neither the alpha nor the beta complex was associated with any developmental anomalies.

In contrast to the developmental characters, no other morphological traits were correlated with complexes. The vegetative morphologies of $O$. laciniata and $O$. grandis are nearly identical (Munz, 1965). No vegetative differences were noted in the hybrids. The floral characters of the selfing $O$. laciniata and the outcrossing $O$. grandis, on the other hand, are quite different. Yet the Fl's are intermediate with no complex-specific differences (table 4).

Table 4

Mean floral characters of hybrids

\begin{tabular}{|c|c|c|c|c|c|c|}
\hline $\begin{array}{c}\text { Cross } \\
\text { (female first) }\end{array}$ & $(n)$ & $\begin{array}{l}\text { Petal } \\
\text { length } \\
(\mathrm{mm})\end{array}$ & $\begin{array}{l}\text { Corolla } \\
\text { tube length } \\
\text { (mm) }\end{array}$ & $\begin{array}{l}\text { Anther } \\
\text { length } \\
\text { (mm) }\end{array}$ & $\begin{array}{c}\text { Filament } \\
\text { length } \\
(\mathrm{mm})\end{array}$ & $\begin{array}{l}\text { Length of } \\
\text { sepal tips } \\
\text { (mm) }\end{array}$ \\
\hline laciniata $\times$ & & $11 \cdot 1 \pm 1 \cdot 1$ & $25 \cdot 0 \pm 1 \cdot 1$ & $4 \cdot 2 \pm 0 \cdot 2$ & $8 \cdot 6 \pm 0 \cdot 3$ & $3 \cdot 9 \pm 0 \cdot 5$ \\
\hline $\begin{array}{l}\text { grandis } \\
\text { grandis } \times \\
\text { laciniata }\end{array}$ & (57) & $12 \cdot 2 \pm 1 \cdot 0$ & $26 \cdot 4 \pm 0 \cdot 8$ & $4 \cdot 5 \pm 0 \cdot 2$ & $9 \cdot 1 \pm 0 \cdot 4$ & $3 \cdot 2 \pm 0 \cdot 2$ \\
\hline $\begin{array}{l}\text { grandis } \\
\text { laciniata }\end{array}$ & $\begin{array}{l}(20) \\
(20)\end{array}$ & $\begin{array}{r}25 \cdot 1 \pm 2 \cdot 1 \\
8 \cdot 4 \pm 0 \cdot 9\end{array}$ & $\begin{array}{l}33 \cdot 9 \pm 1 \cdot 3 \\
23.2 \pm 0.8\end{array}$ & $\begin{array}{l}5 \cdot 9 \pm 0 \cdot 5 \\
2 \cdot 6 \pm 0 \cdot 4\end{array}$ & $\begin{array}{r}13 \cdot 0 \pm 0.6 \\
6 \cdot 2 \pm 0.4\end{array}$ & $\begin{array}{l}3.8 \pm 0.6 \\
1 \cdot 6 \pm 0.2\end{array}$ \\
\hline
\end{tabular}

\section{Discussion}

Both Pgi-1 alleles and characters affecting floral development were shown to be associated with the chromosomal complexes of $O$. laciniata. The alleles of the $b / d, b / f, d / f$, and $d / g$ heterozygotes of the Pgi-1 locus are complex-specific among sibs, within populations, and among the populations tested (tables $2 \& 3$ ). Such non-Mendelian inheritance is expected in a permanent translocation heterozygote because the two chromosomal complexes are transmitted as tight linkage groups (Cleland, 1972).

Surprisingly, in some races of the permanent translocation heterozygotes $O$. biennis and $O$. parviflora, Pgi-1 inheritance is not strictly complex-specific with some variation in transmission due to either recombination or leakage in the lethal system (Levy et al., 1975). Uniformity of inheritance for this locus in $O$. laciniata suggests that the locus is not subject to much recombination and that the balanced lethal system is very effective in this species.

Like $O$. laciniata, the association of alleles to complexes is very strong 
among a variety of races of $O$. biennis $I$ and $O$. biennis $I I$. These species also show complex-specificity from site to site for any given heterozygous genotype (with one exception) not only for Pgi-1 but for five other allozyme loci as well (Levy and Winternheimer, 1977).

The only morphological characters associated with the complexes of $O$. laciniata were those that influenced floral development in the hybrids. In contrast to their parents, many $\mathrm{F}_{\mathbf{1}}$ 's from $O$. laciniat $\times O$. grandis crosses exhibited aborted buds, flowers without anthers, or protogyny (table 2). Aborted buds were usually associated with the alpha complex while the " no anthers" trait and protogyny were usually associated with the beta complex. These developmental anomalies are most likely the result of a mutation or mutations accumulated in $O$. laciniata's complexes which do not affect floral development in their sheltered state but are disharmonious with the genome of $O$. grandis.

No other morphological features, vegetative or floral, were found to be associated with the complexes of $O$. laciniata. In contrast, $O$. biennis has both a variety of lethals and developmental anomalies associated with its complexes as well as complex-specific morphological syndromes which are manifested in vegetative characters (Cleland, 1972). These diagnostic characters associated with $O$. biennis complexes are cited as evidence of a hybrid origin for this species (Cleland, 1972). The situation in O. laciniata parallels more closely that of another permanent translocation heterozygote in the $O$. biennis complex, O. strigosa. Oenothera strigosa also has complexes which are not differentiated much either morphologically or allozymically (Cleland, 1972; Levy et al., 1975; Levy and Levin, 1975). The lack of complex-specific traits in this species and in $O$. laciniata suggests either a nonhybrid origin or a hybrid origin involving very similar populations.

Allelic associations have been demonstrated in other heterokaryotypes. The hybridogenetic fish in the genus Poeciliopsis have a recombination system which parallels that in Oenothera; the maternal complement of chromosomes is always transmitted while the paternal chromosomes segregate at meiosis and are destroyed (Schultz, 1977). No crossing-over occurs among the two sets of chromosomes. In the hybridogenetic Poeciliopsis monachalucida not only are electrophoretic alleles associated with the sheltered maternal genome (Vrijenhoek et al., 1978) but also diagnostic morphological characters and deleterious genes some of which are involved in developmental anomalies (Leslie and Vrijenhoek, 1978; Leslie, personal communication). Like $O$. laciniata these alleles are believed to have accumulated since the origin of the species.

Allozyme alleles often have been found to be associated with inversions in a variety of Drosophila species. "In some of these cases the relationship between the alleles and the inversions was absolute,... while in other cases there was some 'leakage' ... and in other cases different inversions were monomorphic for the same allele" (Hedrick et al., 1978). Yet these inversions are not usually associated with any diagnostic morphological characters.

Thus, $O$. laciniata and other species with rearranged chromosomes indeed have alleles associated with the sheltered portions of the genome. In the case of 0 . laciniata, Pgi-1 alleles are closely associated with the complexes and were probably fixed on the complexes during the genesis of the species because the same alleles are present in its putative progenitor, $O$. grandis 
(Ellstrand, 1978). Thus, O. laciniata and other species with rearranged chromosomes indeed have alleles associated with the sheltered portions of the genome. In the case of 0 . laciniata, Pgi-1 alleles are closely associated with the complexes and were probably fixed on the complexes during the genesis of the species because the same alleles are present in its putative progenitor, 0 . grandis (Ellstrand, 1978). However, the fact that a given allele is sometimes associated with one complex and sometimes with another (table 2) suggests that each inbred line of $O$. laciniata arose as a separate event. The karyotypic heterogeneity of the $\beta$ complex (Hecht, 1950) supports such a hypothesis. Alternatively, very rare crossing-over could produce a similar pattern.

Alleles affecting floral development in hybrids probably arose after the origin of $O$. laciniata because no aberrant floral development has been detected for either intra- or inter-populational crosses of $O$. grandis (Ellstrand, 1978).

Despite the fact that $O$. laciniata is chromosomally a hybrid and shows a strong association of Pgi-1 alleles to its complexes, it is largely homozygous for both morphological traits and several allozyme loci (Ellstrand, 1978), reflecting little differentiation in its chromosomal complexes. Association of alleles to different chromosomal rearrangements does not necessarily imply a disparate origin for those rearrangements.

Acknowledgments.-This paper benefitted from the helpful comments of J. Antonovics, K. Clay, M. Levy, and T. Meagher. This work was supported by PHS grant 5T32 GM 07126-03 to NCE, NSF grant DEB 76-09351 to NCE and DAL, and NSF grant DEB 7619914 to DAL. The work is part of a dissertation submitted to the Division of Biological Sciences of The University of Texas at Austin in partial fulfillment of the requirements for the Doctor of Philosophy degree.

\section{REFERENGES}

CARson, H. 1967. Permanent heterozygosity. Evol. Biol., 1, 143-168.

CHARLESWORTH, B. 1978. Model for evolution of Y chromosomes and dosage compensation. Proc. Natl. Acad. Sci. USA, 75, 5618-5622.

Cleland, R. E. 1968. Cytogenetic studies on Oenothera, subgenus Raimannia. Japan $\mathcal{J}$. Genetics, 43, 329-334.

Cleland, R. E. 1972. Oenothera: Cytogenetics and evolution. Academic Press, New York. Dobzhansky, T. 1970. Genetics of the evolutionary process. Columbia University Press, New York.

ELLSTRAND, N. C. 1978. Evolutionary consequences of permanent translocation heterozygosity in Oenothera. Ph.D. thesis, University of Texas.

GRANT, v. 1956. Chromosomal repatterning and adaptation. Adv. in Genetics, 8, 89-107. GRANT, v. 1964. The architecture of the germplasm. Wiley, New York.

GRANT, v. 1975. Genetics of flowering plants. Columbia Univ. Press, New York.

hays, w. L., and winkler, R. L. 1971. Statistics: Probability, inference, and decision. Holt, Rinehart and Winston, New York.

HECHT, A. 1950. Cytogenetic studies of Oenothera, subgenus Raimmania. Indiana Univ. Publ. Sci. Ser., 16, 225-304.

HEDRICK, P., JAIN, s., AND HOLDEN, L. 1978. Multilocus systems in evolution. Evol. Biol., 11, 101-184.

ISHII, K., AND CHARLESWORTH, B. 1977. Associations between allozyme loci and gene arrangements due to hitch-hiking effects of new inversions. Genet. Res., 30, 93-106.

KOJIMA, K., AND sCHAFFER, H. 1967. Survival process of linked mutant genes. Evolution, $21,518-531$.

LESLIE, J. F., AND VRIJENHOEK, R. C. 1978. Genetic dissection of clonally inherited genomes of Poeciliopsis. I. Linkage analysis and preliminary assessment of gene loads. Genetics 90, 801-811. 
LEVY, M., STEINER, E., AND LEVIN, D. A. 1975. Allozyme genetics in the permanent translocation heterozygotes of the Oenothera biennis complex. Biochem. Genet., 13, 487-500.

LEVY, M., AND LEVIN, D. A. 1975. Genetic heterozygosity and variation in permanent translocation heterozygotes of the Oenothera biennis complex. Genetics, 79, 493-512.

LEVY, M., AND WINTERNHEIMER, P. L. 1977. Allozyme linkage disequilibria among chromosome complexes in the permanent translocation heterozygote, Oenothera biennis. Evolution, 31, 465-476.

LOKKI, J. 1976. Genetic polymorphism and evolution in parthenogenetic animals. VII. The amount of heterozygosity in diploid populations. Hereditas, 83, 57-64.

MULLER, H. J. 1964. The relation of recombination to mutational advance. Mutation Res., $1,2-9$.

munz, P. A. 1965. Onagraceae. North American Flora. Ser. II., pt. 5, 1-231. N.Y. Botanical Garden.

NEI, M. 1970. Accumulation of non-functional genes on sheltered chromosomes. Am. Naturalist., 104, 311-322.

schultz, R. J. 1977. Evolution and ecology of unisexual fishes. Evol. Biol., 10, 277-331. VRIJENHOEK, R. C., ANGUS, R. A. AND SCHUltZ, R. J. 1978. Variation and clonal structure in a unisexual fish. Am. Naturalist., 112, 41-55. 